\title{
MODELOS DE BUSCA, ACESSO, RECUPERAÇÃO E APROPRIAÇÃO DA INFORMAÇÃO NA WEB DE DADOS
}

\section{MODELS OF INFORMATION SEARCH, ACCESS, RETRIEVAL AND APPROPRIATION ON THE WEB OF DATA}

\author{
Francisco Carlos Paletta ${ }^{a}$ \\ José Antonio Moreiro-Gonzales ${ }^{b}$
}

\begin{abstract}
RESUMO
Introdução: A era digital demanda por novas propostas e abordagens técnicas associadas à utilização da Tecnologia da Informação na recuperação e apropriação da informação no contexto da Web de Dados. O desenvolvimento dessa área permitirá um maior entendimento dos recursos da tecnologia colaborativa utilizados em ambientes informacionais digitais na organização da informação e do conhecimento. A inserção dessas tecnologias consiste em inovações que devem estar vinculadas à tradição e à missão das bibliotecas e dos repositórios digitais. Objetivos: Este trabalho tem por objetivo discutir os resultados de projeto de pesquisa conduzido no Departamento de Informação e Cultura da Escola de Comunicações e Artes da Universidade de São Paulo e está estruturado em três fases: (i) Modelos de busca, acesso, e recuperação da informação; (ii) Infraestrutura tecnológica em bibliotecas digitais; e (iii) Ferramentas de busca e recuperação da informação na Web de Dados. Metodologia: Identificar e discutir as tendências nos modelos de busca da informação, em especial interesse aqueles que influenciam o contexto da organização e recuperação da informação, de modo que o uso da tecnologia possa proporcionar a criação e agregação de valor aos modelos de busca, acesso, recuperação e apropriação da informação na Web de Dados. Conclusões: Atualmente se conhece muita coisa sobre planejamento, aquisição, organização, controle e desenvolvimento de coleções, mas muito pouco sobre como o usuário interage com os sistemas ou para que fins, e como a informação, que é a matéria-prima do sistema, está sendo utilizada. Torna-se evidente a necessidade de aprofundar os estudos e pesquisas que permitam entender os modelos de busca e apropriação da informação em um cenário dependente de recursos computacionais na Web inteligente.
\end{abstract}

Descritores: Modelos de Busca da Informação; Recuperação da Informação; Organização da Informação; Usuário da Informação; Tecnologia da Informação; Web de

\footnotetext{
a Doutor em Ciências pela Universidade de São Paulo. Professor da Universidade de São Paulo. E-mail: fcpaletta@usp.br

b Professor na Universidade Carlos III de Madrid. E-mail: jamore@bibuc3.es
} 
Dados.

\section{INTRODUÇÃO}

Os ambientes informacionais digitais, a partir dos quais estabelecemos um processo de produção de conhecimento de forma colaborativa, tem ganhado importância e relevância com a incorporação e o uso das Tecnologias de Informação e Comunicação (TICs), como no caso das bibliotecas e repositórios digitais que armazena, preserva, dissemina e permite o acesso, a apropriação e o uso da informação, gerando novos conhecimentos.

A Web é uma rede com conteúdo interligados através de documentos de hipertexto. Seu mapeamento é possível por processos de análise e coleta sucessiva de páginas de conteúdo a partir de um conjunto de localizações de documentos previamente conhecidos. Tais buscas são feitas de forma automática por programas de computador normalmente denominados crawlers coletores ou batedores. Mesmo neste mapeamento automático, o conjunto inicialmente assumido de localizações a partir do qual a busca é feita influencia o resultado obtido. Além disso, nem toda a Web está interligada: existem muitos subconjuntos de documentos interligados entre si, de tamanhos variados, sem ligação com o restante da rede (ou seja, "ilhas" de informação).

A era digital demanda por novas propostas e abordagens técnicas associadas à utilização da Tecnologia da Informação na apropriação e geração de conhecimento no contexto da Web de Dados.

Espera-se que o desenvolvimento dessa área leve a um maior entendimento dos recursos da tecnologia colaborativa utilizados em ambientes informacionais digitais na organização da informação e do conhecimento. Em qualquer caso, a inserção dessas tecnologias consiste em inovação que deve estar vinculada à tradição e à missão das bibliotecas e dos repositórios digitais.

Adaptamo-nos rapidamente às transformações tecnológicas que, sem percebermos, são inseridas no nosso dia a dia. A nova era da informação, além de mudar a vida particular de cada um, muda também os valores sociais e econômicos da sociedade. Essa transformação tem origem em três fenômenos: a convergência da base tecnológica (processamento digital), a dinâmica da 
indústria (queda de preço, que populariza o uso das máquinas) e o crescimento da Internet (que viabiliza o acesso à informação).

A sociedade da informação reestrutura e reorganiza a sociedade e a economia, sendo um fenômeno global com poder de transformar a sociedade, a economia e a política, pois o tipo de informação disponível interfere diretamente em suas estruturas, tornando (ou não) as distâncias menores, a economia mais atraente e a disparidade social menor (TAKAHASHI, 2000, p. 5).

Inovação é uma vantagem competitiva nessa sociedade, cuja estrutura de trabalho é alterada. A rapidez da difusão de informação traz consigo a constante necessidade de modernização, logo, a aplicação de conhecimento e inteligência nessa dinâmica.

A informação deve ser transformada em conhecimento, sendo a educação continuada o elemento base para que isso ocorra. Portanto, a capacitação pedagógica e tecnológica de educadores deve andar em paralelo ao desenvolvimento de conteúdo local, assim como à preservação da identidade e prioridades nacionais.

Neste estudo, nossa proposta é identificar e discutir as tendências nesse campo, em especial interesse aquelas que influenciam o contexto da organização e recuperação da informação, de modo que, cada vez mais, a tecnologia possa proporcionar a criação e obtenção de valor aos modelos de busca, acesso, apropriação e uso da informação na Web de Dados.

O estudo tem por escopo confrontar a utilização os modelos de busca da informação conhecidos com os resultados de pesquisas científicas de âmbito mundial para melhor entender o usuário da informação na era digital, suas competências informacionais e suas demandas por conhecimento.

\section{USUÁRIOS DA INFORMAÇÃO E COMPETÊNCIA INFORMACIONAL}

No contexto mundial definido pela globalização e pela constante mudança tecnológica, o conhecimento tornou-se a principal riqueza das nações, pode também constituir o principal fator de desigualdade nas sociedades atuais. A Sociedade da Informação é a pedra angular das Sociedades do Conhecimento. O conceito de "sociedade da informação", relacionado à ideia da inovação 
tecnológica, caracteriza-se pelo rápido crescimento da informação disponibilizada e as mudanças ocasionadas pela tecnologia usada para gerar, disseminar, acessar e usar a informação. Por outro lado, o conceito de "sociedade do conhecimento" inclui uma dimensão de transformação social, cultural, econômica, política e institucional, assim como uma perspectiva mais pluralista e de desenvolvimento, expressando a complexidade e o dinamismo das mudanças que estão ocorrendo. O conhecimento não só é importante para o crescimento econômico, mas também para fortalecer e desenvolver todos os setores da sociedade.

A expressão Competência Informacional, ou Information Literacy, tem suas origens no estudo da sociedade da informação, e está ligada à necessidade de se desenvolver nos indivíduos aptidões sobre habilidades e competências relacionadas ao acesso, uso e disseminação da informação, objetivando fazer uso desta de forma ética e eficiente, para que o ser humano através de seu intelecto e processo cognitivo possa produzir novo conhecimento (CAMPELLO, 2003).

A noção de fácil acesso à informação propiciado por avanços da tecnologia de redes de computadores e de telecomunicações criou uma noção errônea do imperativo tecnológico como resposta às deficiências comunicacionais e educacionais da humanidade.

O conhecimento e o uso deste ferramental tecnológico são essenciais nos dias de hoje, porém é preciso considerar que por si só a tecnologia não leva à comunicação e à educação. A competência informacional está fortemente relacionada ao processo de interiorização de conhecimentos, habilidades e valores ligados à informação e ao aprendizado. Em um contexto mais prático, representa um conjunto de habilidades necessárias para localizar, interpretar, analisar, sintetizar, avaliar e comunicar a informação em diferentes ferramentas e suportes (DUDZIAK, 2003).

Indivíduos têm seus estoques de informação e estes são usados para compreender as informações externas e as diferentes situações em que se encontram em dado momento. O comportamento de busca e uso de informação são modelados, do ponto de vista epistemológico, pelas características 
cognitivas do indivíduo e por fatores que geram o encontro do usuário com os sistemas de informação ou as consequências de tal confronto.

É preciso atentar para o fato de que não é possível mais se limitar à tarefa de localizar fontes de informação. É necessário levar em consideração tarefas de interpretação, formulação e aprendizagem envolvidas no processo de busca dessa informação. $O$ aumento no acesso à vasta quantidade de informação requer, entretanto, serviços que se centrem no significado da busca mais do que meramente na localização da fonte. Nessa perspectiva, os usuários da informação não podem ser vistos apenas como integrantes do sistema, mas como a "razão de ser" do serviço de informação (MELO; ARAUJO, 2007).

Sistemas de informação organizados na perspectiva tradicional concentram-se prioritariamente na aquisição e administração de grandes coleções de materiais. Assumiu-se, durante décadas, que as atividades técnicas dos sistemas eram o seu ponto estratégico. Considerava-se que os usuários utilizavam o sistema exatamente da maneira como estes tinham sido projetados. Não se imaginava indagar, aos sistemas, questões imprescindíveis sobre a identidade e propósitos principais de seus usuários.

Como a informação era considerada algo existente fora das pessoas e passível de ser transferida de uma para outra, parecia ser possível que eficiência e sucesso das operações de um sistema pudessem ser medidos em função do número de fontes de informações recuperadas pelo sistema versus o que realmente foi de interesse do usuário.

Isso, na realidade, coloca novamente o usuário como um processador imperfeito da informação, pois é já sabido que nem todas as pessoas se interessam pelas mesmas fontes indicadas. Resulta desse procedimento que hoje em dia se conhece muita coisa sobre planejamento, aquisição, organização, controle e desenvolvimento de coleções, mas muito pouco sobre como as pessoas fazem uso dos sistemas ou para que fins e como a informação, a matéria-prima dos sistemas, está sendo utilizada (FERREIRA, 1995).

Literacia informacional tem constituído, nos últimos anos, novo campo de pesquisa que interessa à educação, à ciência da informação e às ciências cognitivas. O desafio está em inicialmente aprender a utilização básica dos 
recursos tecnológicos - literacia digital - e a seguir apropriar-se dos mesmos para gerar novos conhecimentos - literacia informacional.

\section{ORGANIZAÇÃO DA INFORMAÇÃO E DO CONHECIMENTO NA WEB DE DADOS}

O impacto do uso da Web na sociedade, nos indivíduos e nas organizações tornou-se objeto de pesquisa, extrapolando o campo especializado da computação aplicada, e atingindo áreas de estudos organizacionais e sociológicos. Por ser essencialmente dinâmica e sem fronteiras, tanto do ponto de vista físico como virtual, é importante que seja conhecida em detalhes, tanto para assegurar sua livre transformação quanto para permitir sua disponibilidade, confiabilidade e acessibilidade por todos.

O primeiro princípio da Web, proposto pelo Consórcio World Wide Web W3C Brasil (2011) afirma

O principal valor da Web é o social. Mais do que tecnológico, este é um ambiente de comunicação humana, de transações comerciais, de oportunidades para compartilhar conhecimentos e, para ser um ambiente universal, deve estar disponível para todas as pessoas, independentemente dos equipamentos e softwares que utilizem, principalmente da cultura em que se inserem da localização geográfica, das habilidades físicas ou mentais, das condições socioeconômicas ou de instrução.

A universalidade da Web só pode ser garantida e aprofundada com um modelo de governança democrático e pluralista que tenha foco no acesso por todos e na sua própria evolução tecnológica (CGI.BR/NIC.BR, 2011).

A denominada Web 2.0 segue uma filosofia com princípios de leitura e escrita de natureza participativa, em que cada usuário pode intervir diretamente na escolha e introdução de dados no âmbito de cada site; é cooperativa, uma vez que compartilha ideias, preferências, informações e conhecimento; é interativa, na medida em que, através de toda a gama de recursos multimídia, é possível um diálogo simultâneo com os usuários; é democrática, pois sob essa filosofia existe liberdade de expressão, de pensamento, e, sobretudo, de trânsito de informações, independentemente dos interesses de cada um; é também sociotécnica, pois, através de todas as suas características, é possível um 
intercâmbio de culturas, religiões, etnias e outros. Hoje, não só o usuário participa como também adiciona conteúdo que ao serem compartilhados em outros recursos colaborativos passam a receber comentários dos membros vinculados a sua comunidade agregando valor à informação compartilhada, além de criar vários caminhos para a localização do próprio recurso. Assim, temos uma nova relação e interação na qual aumenta o nível sofisticado de atitudes sociais eletrônicas.

Saberes científicos e o acesso a inovações tecnológicas apresentam-se distribuídos de forma muito desigual, considerando-se nesta comparação países, regiões, estratos sociais, faixas etárias, níveis educacionais, dentre outros. Assim, a problemática da diversidade cultural e os estudos sobre ela devem fazer parte da consideração teórica, da investigação empírica e do planejamento de políticas na área de fomento à Competência Informacional. Além disso, o usuário da informação típico não deseja apenas extrair informações específicas e definitivas no menor tempo possível ou, alternativamente, se dispõe a investir esforço para buscar e explorar informação e conhecimento. A verdade é que as pessoas oscilam continuamente entre extrair e explorar, e o uso da informação é um processo confuso, desordenado, sujeito aos caprichos da natureza humana, como qualquer outra atividade (CANCLINI, 2009). Entre os elementos mais importantes que influenciam o uso da informação estão às atitudes do indivíduo em relação à informação e a sua busca, atitudes essas que são fruto da educação, do treinamento, da experiência passada, das preferências pessoais.

A Ciência da Informação tem como objetivo a organização da informação, assim como seu acesso e processo de disseminação por meio das diferentes tecnologias aplicadas às plataformas de informação e comunicação, voltada à prática científica e profissional no âmbito social e individual. Por isso a necessidade de estar inserida no campo da Teoria da Informação (estrutura) e na Teoria da Comunicação (mensagem).

A organização do conhecimento liga os três processos de uso estratégico da informação - a criação de significado, a construção do conhecimento e a tomada de decisões - num ciclo contínuo de aprendizagem e adaptação que 
podemos chamar de ciclo do conhecimento.

A informação é a representação simbólica de um fato ou uma ideia capaz (ou não) de alterar o conhecimento, cujo valor e definição só podem ocorrem de acordo com o contexto em que está inserida, portanto, ela pode ser tomada em três diferentes usos:

\section{Quadro 1 - Usos da Informação}

\section{Como Processo}

quando, no ato de informar, ao saber de algo o conhecimento é modificado

\section{Como Conhecimento} quando se obtém uma informação que transforma o conhecimento

Como Coisa quando a informação é apenas um dado

Fonte: Projeto de Pesquisa

Há também diferentes episódios que levam o usuário a buscar informação, que influenciam no modo como esta é tratada e que mudam constantemente:

\section{Quadro 2 - Motivos de Busca da Informação}

\section{Cognitivo}

quando há uma interação usuário-informação, pois esta é obtida cognitivamente e interpretada.

Situacional

quando uma situação cria no usuário a necessidade de busca por informação. Emocional

quando o usuário interage com as intenções e motivações associadas a outros sentimentos relacionados à busca pela informação, como satisfação ou frustração.

Fonte: Projeto de Pesquisa

À medida que existe uma reação que afeta a relação do usuário com a informação, consequentemente, o sistema de busca é afetado, pois os modos de busca podem ser alterados numa constante tentativa de recuperação daquilo que se procura.

O desenvolvimento tecnológico trouxe novas necessidades e novos problemas para armazenar e recuperar informação, sendo a Ciência da Informação um dos meios bem-sucedidos para solucionar essa questão, e a representação, a busca e os sistemas de operação da informação os pontoschave relevantes até hoje nesse campo de estudo. Advindos dessa ciência, a organização e a representação do conhecimento é o que torna viável gerar 
instrumentos para a recuperação da informação - estando devidamente registrada fisicamente, no caráter de documento -, formando um ciclo: o conhecimento organizado (socializado) é registrado como informação passível de ser recuperada (disponível) para gerar novo conhecimento, pois a informação necessita de um suporte para ser transmitida (impresso, digital, sonoro, visual) e utiliza os sistemas de linguagem para ser decodificada (linguagem documentária). Ela é produzida por uma pessoa que gera conhecimento para outra pessoa.

Bibliotecas estão desenvolvendo continuamente processos e serviços de forma a explorar os benefícios da Web 2.0. Library 3.0 refere-se a bibliotecas utilizando tecnologias como a web semântica, a computação em nuvem, dispositivos móveis, e re-imaginando o uso de tecnologias estabelecidas, tais como pesquisa federada (RFID), para facilitar a disseminação do conteúdo gerado pelo usuário e a colaboração para promover e fazer coleções de bibliotecas acessíveis. O resultado da Biblioteca 3.0 é a expansão da "biblioteca sem fronteiras", onde as coleções podem ser feitas facilmente disponíveis aos usuários da biblioteca, independentemente da sua localização física. Biblioteca 3.0 é um complemento virtual para os espaços físicos da biblioteca (BELLING et al, 2011).

A fragmentação e a constante transformação da dinâmica do conhecimento dependem dos processos e políticas de atualização da Ciência da Informação, o que torna muito difícil ao profissional da área acompanhar eficientemente todas essas modificações. A produção de representação de recursos informacionais, atividade relacionada à Organização da Informação, é um facilitador da medição qualificativa desse fenômeno, pois expõe o usuário, as suas necessidades e as informações potencialmente relevantes em sua busca dentro de um determinado sistema. (SQUIRRA, 2005).

A representação assume diversos significados, de acordo com o campo que a detém. De modo geral, há um consenso de que ela aponta para uma relação ao objeto a que se refere, mas têm no emissor, no objeto em si e no receptor, noções de valores diferentes, pois a cada um cabe uma interpretação de mundo diferente. "A representação então relaciona o objeto que ela 
representa com a mente que o percebe." (MARCONDES, 2001 apud GARCIA, 2007, p. 37). A representação também ocorre em forma de ícones ou imagens; e sua compreensão ocorre por meio de regras que acentuam ou suprimem algumas características do objeto/documento para que o ele seja identificável.

As representações podem ser divididas em três tipos de fontes: são primárias as fontes originais, as representações de seus autores, no âmbito da expressão; estas se tornam secundárias ao serem transformadas em registros de conhecimento por meio de tratamento documental; e passam a ser terciárias ao tornarem-se passíveis de recuperação e recuperadas em sistemas documentais.

Entretanto, como aponta Buckland (1991 apud GARCIA, 2007, p. 34), é importante salientar algumas características das representações da informação na Ciência da Informação (embora se insira em diferentes ciências, como: Semiótica, Semiologia, Linguística, Ciência da Computação e outras):

[...] elas são, de algum modo, incompletas, na medida em que refletem apenas um ponto de vista, o que faz com que algo do original se perca, sua finalidade é facilitar o armazenamento, a compreensão e a busca; exercem o papel de réplica ou substituto do documento original; seus detalhes adicionais sempre dizem respeito apenas ao documento referenciado; podem ser repetidas; são breves.

São atores envolvidos na atividade de organização da informação os autores e os profissionais da informação, pois ela compreende, para a sua execução, tanto o conhecimento temático (tratamento do conteúdo) quanto o teórico (tratamento físico, descritivo). O primeiro visa à recuperação do que está expresso no texto, enquanto o segundo foca-se na acessibilidade ao documento.

A interação do usuário com o sistema para o reconhecimento do produto final é o que caracteriza o comportamento de busca de informação. Segundo Rowley (2002 apud GARCIA, 2007, p. 40-41), todas as etapas se dão em quatro processos: Representação descritiva, Representação temática, Registro de metadados, Armazenamento e processo de recuperação.

Embora o campo da recuperação da informação ${ }^{1}$ tenha crescido nos últimos anos, os usuários ainda têm dificuldade em utilizar os sistemas de busca,

1 Área de pesquisa que se preocupa com a estrutura, análise, organização, armazenamento, recuperação e busca de informação (SALTON, 1968 apud BEPPLER, 2008). 
realizando consultas inadequadas em decorrência da pouca interatividade que tais sistemas oferecem, o que acarreta em consumo de tempo e intolerância em investigar mais detalhadamente os resultados recuperados. Com foco nessa inter-relação, as pesquisas em information seeking ${ }^{2}$ pensam meios de tornar a busca pela informação mais fácil, com melhor desempenho e de modo intuitivo.

Entretanto, construir sistemas de busca não é uma tarefa simples, pois, além de competência na área de recuperação da informação, é necessário ter conhecimento sobre as informações da área do domínio e considerar o comportamento humano dinâmico no processo de busca. A engenharia do conhecimento visa à construção de mecanismos que tornem mais eficientes a manipulação e o gerenciamento do conhecimento, com ferramentas que permitam que ele possa ser explorado. O que as fontes de informação não estão aptas a processar é a dinamicidade do usuário, que a cada interação vê surgir novas ideias e novas necessidades de consulta.

A cada estágio de interação os usuários não estão apenas alterando os termos de uma consulta, eles estão em um processo de mudança contínua tanto das ações a serem tomadas, baseadas em um determinado resultado, quanto da necessidade em seu conjunto. (BEPPLER, 2008, p. 8).

$\mathrm{O}$ ambiente informacional deve atender às diversas necessidades de diferentes usuários e, para tal, prover múltiplas formas de representação. Ele deve prever também a economia de energia nessa busca, para que o resultado final da recuperação da informação seja feliz. Por isso, a representação deve sempre estar focada no usuário e não se caracterizar como uma simples resposta à demanda e à entrega de informação, mas à eficácia envolvida em todo o processo.

\section{RECUPERAÇÃO DA INFORMAÇÃO}

Segundo Lancaster (1993, p. 202 apud LOPES, 2002, p. 60), a evolução histórica dos sistemas de recuperação da informação apresenta duas linhas de

\footnotetext{
$2 \mathrm{O}$ termo sofre diferentes definições por diversos autores. No geral, eles concordam com a acepção de que se refere à tomada de decisão de uma pessoa, à busca de informação para suprir uma necessidade ou a falta de conhecimento em determinado assunto quando esta é identificada.
} 
desenvolvimento: a primeira tem base nos sistemas das instituições National Library of Medicine (NLM), Department of Defense (DOD) e National Aeronautics and Space Administration (Nasa), que utilizavam tesauros específicos de áreas temáticas para indexação; e a segunda no campo do Direito, que envolvia a criação de bases de dados com os textos completos das leis. Ambas exigiam planejamento acurado da busca, respeitando os resultados esperados pelos usuários.

A Recuperação da Informação está no cerne da Ciência da Informação. Ela objetiva, como o próprio nome sugere, entender os processos de recuperação da informação para aprimorar e facilitar os sistemas de busca, promovendo melhores resultados para os usuários.

Há duas linhas de pesquisa nessa área: uma focada na abordagem computacional, baseada em softwares (com interface de busca, banco de dados e mecanismos de busca); e outra, centrada no usuário e em seu comportamento de busca, baseada na recuperação e na qualidade/confiabilidade da informação. A diferença crucial entre ambas as perspectivas é que a primeira entende que $o$ sistema recupera a informação, enquanto plataforma de busca, e a segunda entende que é o usuário quem a recupera, pois a informação consiste na relação que ocorre entre sujeito de busca e objeto buscado. A segunda linha amplia os limites da recuperação da informação, uma vez que incorpora o caráter humano aos estudos.

Buscar informação compreende uma estratégia de busca com técnicas que tornam possíveis a conexão entre uma pergunta formulada e uma base de dados, ou num esquema simplificado, como mostra o quadro 3 :

\section{Quadro 3 - Estratégia de Busca da Informação}

\section{Representação}

Informação potencial em linguagem documentária como registro de metadados
Função de comparação

Comparativo da representação da questão com a representação dos documentos recuperados

\section{Questão}

Requerimento para informação em linguagem natural / de interrogação

Fonte: Ingwersen (2002 apud GARCIA, 2007, p. 47). - Adaptação do Autor

O problema reside na localização da informação correta, pois no resultado da busca são gerados documentos e partes de documentos com diferentes níveis de relevância e significado referentes à informação buscada. Daí o papel crucial do profissional da informação, como aquele que possui discernimento 
para avaliar a pertinência do que é útil em determinado contexto, o que lhe exige maior conhecimento da comunidade usuária com a qual trabalha.

No meio dos extremos usuário-sistema, a interface age como auxiliar ao profissional da informação, intermediando os dois polos e propiciando a comunicação. É nessa interação que a Recuperação e a Organização da Informação se intersectam, pois a primeira contribui com subsídios para o estudo do usuário, indicando seu comportamento no processo de busca; enquanto a segunda contribui com o desenvolvimento de interfaces que reduzem a complexidade no processo de busca.

A constante evolução da tecnologia digital tem mudado o comportamento da busca da informação, da postura do usuário frente aos novos sistemas e dos canais de informação. Embora as ferramentas da web aumentem o aparato de possibilidades de armazenamento, elas exigem que todos os envolvidos no assunto tenham competência para operacionalizá-las, o que afeta diretamente os processos de representação e organização, armazenamento e representação e busca da informação.

As linguagens documentárias são as responsáveis pela construção das interfaces (softwares) que conectam as informações dos documentos (inseridos num sistema) e o usuário (em seu contexto) num sistema de hipertexto. Houve um tempo em que se pensava que a informática era apenas uma ferramenta de cálculo, sem potencialidades como tecnologia intelectual. O avanço tecnológico, entretanto, mudou essa visão e permitiu que ela fosse muito, além disso.

O hipertexto tem similaridade com os processos do pensamento e da memória humana, na medida em que funciona como uma contiguidade, embora não sequencial, de associações que se ligam numa organização própria - ou não organização, ou não linear - e que necessitam de armazenamento. Ele traz portas que abrem caminhos dentro do documento. Paralelamente ao texto impresso, este apresenta estrutura formal linear, com palavras que formam frases que formam parágrafos e assim por diante, enquanto aquele traz informações armazenadas em cada célula de sua composição, podendo levar a diferentes entradas, como gráficos, imagens, sons e outras. Além disso, essa dinâmica ocorre por meio eletrônico e pode sempre ser alterada, o que muda 
completamente a relação e a interação que se tem com o texto.

É todo o contexto que define as necessidades de informação de um indivíduo, pois este necessita executar determinadas tarefas nos diferentes ambientes e momentos em que atua para atingir seus objetivos (GARCIA, 2007), entretanto, a grande dificuldade está em como se fazer isso.

É imprescindível concentrar-se no usuário e seu contexto para o melhor desenvolvimento do hipertexto, pois somente assim é possível reduzir seu esforço no momento da busca e evitar que ele se perca numa infinidade de links e esteja mais bem orientado na navegação, otimizando a utilização do conhecimento.

\section{METODOLOGIA}

A seguir apresentamos os aspectos relacionados à metodologia utilizada, a estratégia de coleta, tratamento e análise dos dados, introduzindo os tópicos relativos aos objetivos, métodos e instrumentos de pesquisa. Esta prospecção não tem caráter experimental, mas exploratório, em razão principalmente da atualidade e emergência do tema e à incipiente bibliografia existente tanto no país como no exterior. Um aspecto qualitativo-quantitativo também será investigado.

\subsection{MÉTOdo da Pesquisa}

O pesquisador utiliza a metodologia científica para a obtenção de novos conhecimentos no campo da realidade social. A elaboração e o desenvolvimento da pesquisa necessitam, para que os resultados sejam satisfatórios, estarem baseadas em planejamento cuidadoso, reflexões conceituais sólidas e alicerçados em conhecimentos existentes.

Para Gil (1991, p. 42), a pesquisa deve ser pragmática, um "processo formal e sistemático de desenvolvimento do método científico. O objetivo fundamental da pesquisa é descobrir respostas para problemas mediante 0 emprego de procedimentos científicos". Tendo em vista o objeto deste trabalho conforme descrito inicialmente, é importante, neste instante, estabelecer a 
relação entre a metodologia científica e a utilização desta para estudar os fenômenos sociais.

Entende-se por Metodologia Científica um conjunto de etapas ordenadamente dispostas que o pesquisador deve executar na investigação de um fenômeno. Inclui a escolha do tema, o planejamento da investigação, o desenvolvimento metodológico, a coleta e a tabulação de dados, a análise dos resultados, a elaboração das conclusões e a divulgação de resultados.

Método Científico é o conjunto de processos ou operações mentais que se devem empregar na investigação. É a linha de raciocínio adotada no processo de pesquisa. Os métodos que fornecem as bases lógicas à investigação são: dedutivo, indutivo, hipotético-dedutivo, dialético e fenomenológico (GIL,1991; LAKATOS; MARCONI, 1991). Partindo dessas concepções, é possível então apresentar a metodologia utilizada neste estudo.

\subsection{PARAdigmas}

A pesquisa será estabelecida a partir de referenciais teóricos e da experiência de estudiosos no assunto, entre pesquisadores e bibliotecas, um conjunto de ferramentas de estudo mais utilizadas aliada à elaboração de perguntas para usuários da informação a partir das quais será possível, com base no paradigma teórico oriundo da revisão da literatura, estruturar o método de coleta de dados que verificará na prática as proposições referenciais.

O estudo tem por escopo confrontar a utilização os modelos de estudo de usuários da informação conhecidos com os resultados de pesquisas científicas de âmbito mundial para tentar conhecer e entender melhor as formas de acesso, apropriação e uso da informação em ambiente Web.

A população ou universo da pesquisa incluiu as Bibliotecas da Universidade de São Paulo que possuem as mesmas características definidas para este estudo. A pergunta que esta pesquisa se propõe a estudar e responder é: "quais os modelos de acesso, apropriação e uso da informação utilizados pelos usuários da informação baseados na Web"? Os resultados desta pesquisa poderão servir de base para a orientação de novos Serviços ao Usuário propostos pela Biblioteca e/ou Unidade de Informação no cenário fortemente 
dependente da Web.

\subsection{O Instrumento de Pesquisa}

Os critérios de escolha e a estratégia de coleta e análise dos dados convergem para o instrumento de pesquisa, que será desenvolvido a partir do equacionamento das dimensões e fronteiras investigadas na pesquisa de campo e que serão, para ser devidamente perscrutadas, particionadas em três enfoques primordiais, subdivididos de acordo com a conveniência e importância do assunto: Modelos de Busca e Comportamento Informacional; Identificação da Infraestrutura Tecnológica das Bibliotecas Digitais; Entendimento das Ferramentas de Busca Baseada em Serviços Web na busca, acesso, recuperação e apropriação da informação.

Figura 1 - Dimensões de estudo consideradas no projeto de pesquisa

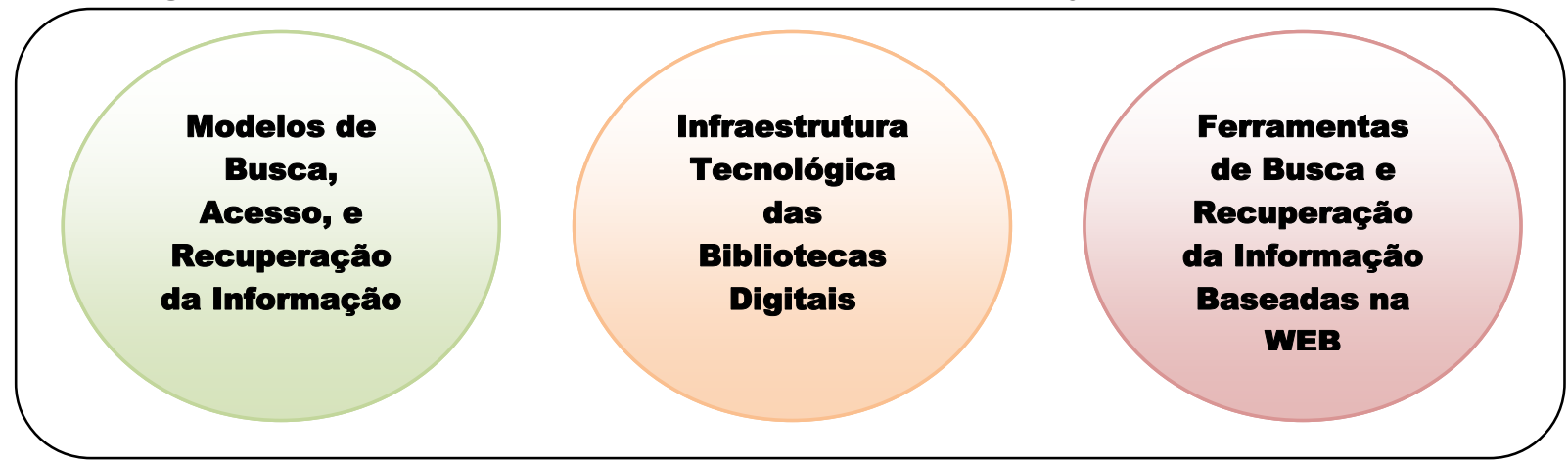

Fonte: Projeto de Pesquisa

Com base na ótica definida para entender o problema da pesquisa, desenvolveremos um questionário que será elaborado por meio digital e enviado aos usuários dos Serviços de Informação das Bibliotecas e/ou Centros de Informação participantes da amostra em estudo.

\section{RESULTADOS}

Neste trabalho apresentamos os resultados da primeira fase do projeto de pesquisa: Modelos de Busca, Acesso, e Recuperação da Informação.

Com base nos recursos identificados e coletados em bibliotecas e repositórios digitais deseja-se observar como são aplicados os recursos da 
tecnologia colaborativa no contexto da Web Semântica ou Web Inteligente também chamada de Web 3.0. A inserção dessas tecnologias apresenta-se como inovação que devem estar vinculadas à tradição e a missão das bibliotecas e dos repositórios de informação. Avaliar a flexibilidade das estruturas computacionais, sua atratividade e dinâmica na qual o usuário torna-se agente na construção de seu ambiente, demandando recursos de customização e personalização na criação de Serviços de Informação inovadores e que permitam que a Biblioteca continue a ocupar papel relevante na produção de novos conhecimentos por parte de seus Usuários (PALETTA; PELISSARO, 2015)

Para tanto, torna-se fundamental compreender como o usuário da informação se apropria dos modelos de busca, acesso e recuperação da informação.

\subsection{MAPEAMENTO dos Modelos de BusCA dA INFORMAÇÃo}

A Biblioteconomia e Documentação estão a serviço da informação e, para tal, utiliza meios para sua organização e recuperação. No que diz respeito à web, as antologias ou taxonomias virtuais são modelos de organização, pois funcionam como ferramentas para classificação. É preciso haver organização dos conceitos para armazená-los, com relações significativas entre eles, formando uma unidade, e os estudos sobre modelos conceituais auxiliam nessa organização. Portanto, faz-se necessário saber que:

[...] um modelo conceitual [...] é uma ferramenta de organização da informação, capaz de representar ideias ou conceitos na forma de um diagrama hierárquico escrito ou gráfico e capaz de indicar as relações entre os conceitos, procurando refletir a organização da estrutura cognitiva sobre um determinado assunto. (LIMA, 2004c apud GARCIA, 2007, p. 67-68).

Os inúmeros sistemas de processamento da informação disponíveis contribuíram para o aumento das relações das informações e dos próprios sistemas em ambientes digitais, contudo, ainda é prescindível melhorar as ferramentas de atendimento às necessidades do usuário. Os documentos já estão interconectados, restando agora torná-los mais intuitivos para serem manipulados por humanos. Segundo Garcia (2007, p. 70), são considerados nos 
modelos de busca e recuperação da informação:

- Tesauro convencional: instrumento de indexação que não opera com o significado dos conceitos, agindo apenas como ferramenta de manipulação (representação, busca e recuperação) de documentos.

- Tesauro facetado: instrumento de indexação com estruturas hierárquicas de classificação independentes, possibilitando a captura por diferentes propriedades dos documentos, inclusive seus aspectos mais relevantes.

- Sistema conceitual de indexação: extensão da estrutura dos tesauros, porém composto por uma série de conceitos que têm a cada par um conceito comum.

- Hiperíndice semântico: instrumento de indexação em que "os conteúdos dos documentos são representados por um 'conjunto de termos de indexação' formado a partir do próprio documento, com os termos de indexação vinculados entre si".

- Rede de referência: formada por uma rede representativa de documentos e outra rede de perguntas demandadas pelo usuário, que são confrontadas durante o processo de busca.

- Rede semântica: possui estrutura semelhante à de uma rede hipertextual, porém sua organização é mais rica e suporta diferentes mecanismos de dedução.

- Ontologia: descreve conceitos e suas associações em um agente de software da web, possui analogia com tesauros e classificações conceituais, pois estabelece relações entre os conceitos, com a diferença de permitir representar e argumentar conhecimentos certos e imutáveis mediante regras de inferência.

O Comportamento Informacional está diretamente relacionado ao comportamento humano na busca, coleta, recuperação, organização e uso da informação e, como todo modelo, pretende ser uma representação sob determinado ponto de vista. Logo, cada conteúdo depende da perspectiva abordada, sendo as principais: cognitiva, social, sociocognitiva e organizacional (CAREGNATO; CRESPO, 2003). 
Há, basicamente, duas categorias para modelos de recuperação da informação: modelos semânticos (análise semântica e sintática para análise da linguagem natural) e modelos estatísticos (medidas estatísticas e comparação entre consulta e documento). Sem se estender a suas especificidades, estão entre os modelos mais comuns: boleano, booleano estendido, vetorial, probabilístico, difuso, de indexação semântica latente e de processamento de linguagem natural. Todos eles, em diferentes modos e medidas, estão presentes nos modelos de busca desenvolvidos ao longo das pesquisas e tentativas de aprimoramento da recuperação da informação.

Recentemente, isso tem mudado, e a preocupação com o usuário, as necessidades de informação do indivíduo e os múltiplos comportamentos de busca passaram a ser o foco central. Os modelos só passaram a emergir, de fato, quando as pesquisas tomaram caráter qualitativo, relacionadas ao comportamento humano.

A seguir, as principais características dos modelos de comportamento de busca apresentados por Wilson, Kuhlthau, Dervin, Ellis, e Ingwersen (apud GARCIA 2007):

- Modelo de Comportamento de Busca: modelo que tem como proposição que a necessidade da informação provém de uma necessidade básica anterior do indivíduo - seja fisiológica, cognitiva ou afetiva - e que este pode encontrar diferentes barreiras no decorrer de sua busca. As hipóteses, por sua vez, estão somente implícitas (Figura 1). (WILSON, 1981 apud GARCIA 2007). 
Figura 2 - Modelo de comportamento de busca.

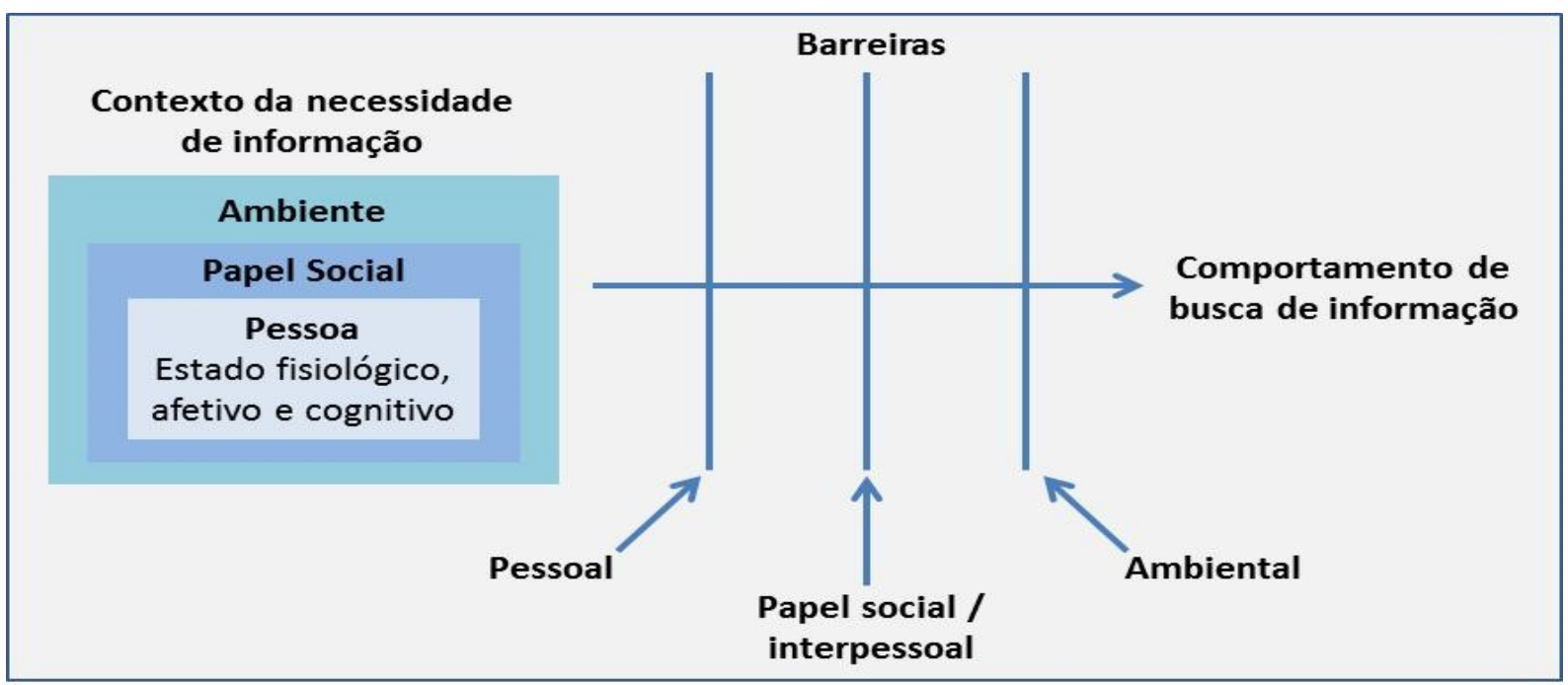

Fonte: Wilson (1981, apud GARCIA, 2007, p. 83) - Adaptação do Autor

- Modelo Geral de Comportamento de Busca: neste modelo revisado é apresentado um ciclo de atividades de informação, com ativadores, interferências e influências significantes nos diferentes comportamentos informacionais e teorias de motivação por trás de cada comportamento de busca. O usuário em foco tem uma necessidade que precisa ser sanada, porém há várias intervenções que afetam os mecanismos e ativam o comportamento de busca (Figura 2). (WILSON, 1996 apud GARCIA, 2007).

Figura 3 - Modelo geral comportamento de busca.

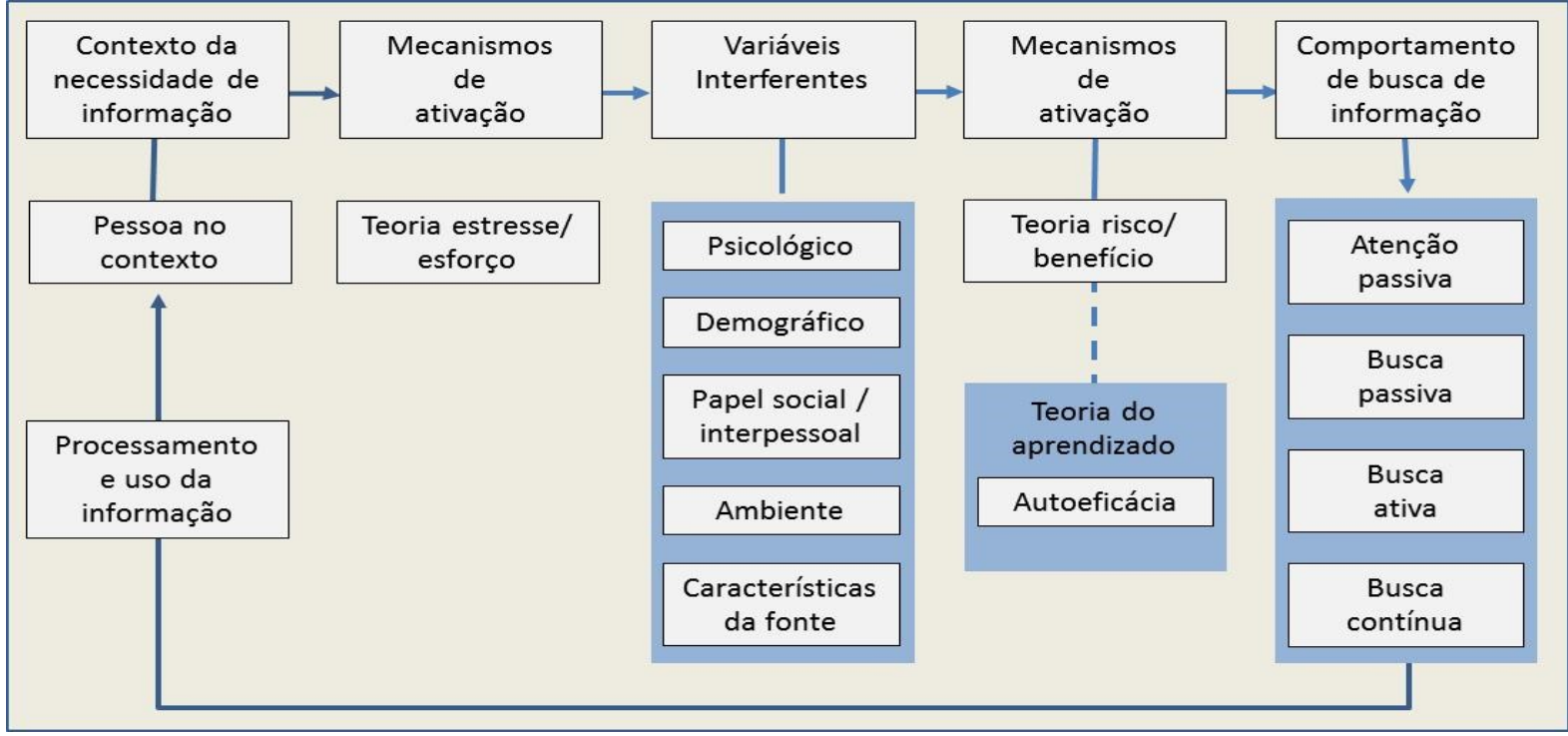

Fonte: Wilson (1996 apud GARCIA, 2007, p. 85) - Adaptação do Autor 


\section{- Processo de Busca da Informação / Information Search Process}

(IPS): modelo que associa várias fases do processo de busca de informação aos sentimentos, pensamentos e ações do usuário, considerando o processo de construção da visão dos indivíduos a partir da assimilação da nova informação, ou seja, ele e sua bagagem de conhecimento (juntamente à cognição e sentimentos afetivos) constroem o significado da informação. Sua premissa é a incerteza, alterada com o estado de conhecimento, que faz aumentar o sentimento de confiança (Figura 3) (KUHLTHAU, 1993 apud GARCIA, 2007).

Divididos em seis etapas, os estágios são encadeados e respeitam uma ordem de ocorrência - uma hipótese de tal observação é a característica de um grupo primário em pesquisa (graduandos), com problemas básicos de informação.

Início: há o reconhecimento da falta de conhecimento, não se sabe exatamente o que é preciso e os pensamentos são vagos - incerteza, apreensão e ansiedade.

Seleção: fase de identificação e seleção dos tópicos gerais a serem investigados.

Exploração: busca por informações relevantes a respeito de um tópico genérico - confusão, incerteza e dúvida.

Formulação: momento decisivo de direcionamento para o estudo menos incerteza e mais confiança.

Coleta: senso de direção definido e maior interação usuário-sistema confiança.

Apresentação: fase final do processo, em que são verificados os níveis de relevância e redundância das informações encontradas - alívio, satisfação ou descontentamento. 
Figura 4 - Processo de Busca da Informação

\begin{tabular}{|c|c|c|c|c|c|c|}
\hline Tarefas & Iniciação & Seleção & Exploração & Formulação & Coleção & Apresentação \\
\hline $\begin{array}{l}\text { Sentimentos } \\
\text { (afetivo) }\end{array}$ & Incerteza & Otimismo & $\begin{array}{l}\text { Confusão } \\
\text { Frustração } \\
\text { Dúvida }\end{array}$ & Clareza & $\begin{array}{l}\text { Senso de } \\
\text { direção, } \\
\text { confiança }\end{array}$ & $\begin{array}{c}\text { Satisfação } \\
\text { ou } \\
\text { Desapontamento }\end{array}$ \\
\hline \multirow[t]{2}{*}{$\begin{array}{l}\text { Pensamentos } \\
\text { (cognitivo) }\end{array}$} & \multicolumn{6}{|c|}{ Vago $\longrightarrow$ Focado } \\
\hline & & & & \multicolumn{3}{|c|}{ Aumento de interesse $\longrightarrow$} \\
\hline $\begin{array}{l}\text { Ações } \\
\text { (físico) }\end{array}$ & \multicolumn{3}{|c|}{$\begin{array}{l}\text { Busca pertinente de informação, } \\
\text { explorando }\end{array}$} & $\longrightarrow \begin{array}{l}\text { Busca } \\
\text { docur }\end{array}$ & \multicolumn{2}{|c|}{$\begin{array}{l}\text { Busca pertinente de informação, } \\
\text { documentando }\end{array}$} \\
\hline
\end{tabular}

Fonte: KUHLTHAU, 1993 apud GARCIA, 2007 - Adaptação do Autor

Modelo Sense-Making: modelo mais voltado ao usuário que à busca, pois considera haver diferentes comportamentos e contextos dos indivíduos, mesmo que estes estejam inseridos no mesmo ambiente e com interesses comuns. Ele considera uma situação, uma lacuna (incerteza), um resultado e uma ponte (entre a situação e o resultado). Ou seja, a necessidade da informação se insere na percepção de uma lacuna do conhecimento a ser sanada. Existe, portanto, um desconforto cognitivo perante a um problema (Figura 4). (DERVIN, 1986 apud GARCIA 2007).

\section{Figura 5 - Estrutura Sense-Making}

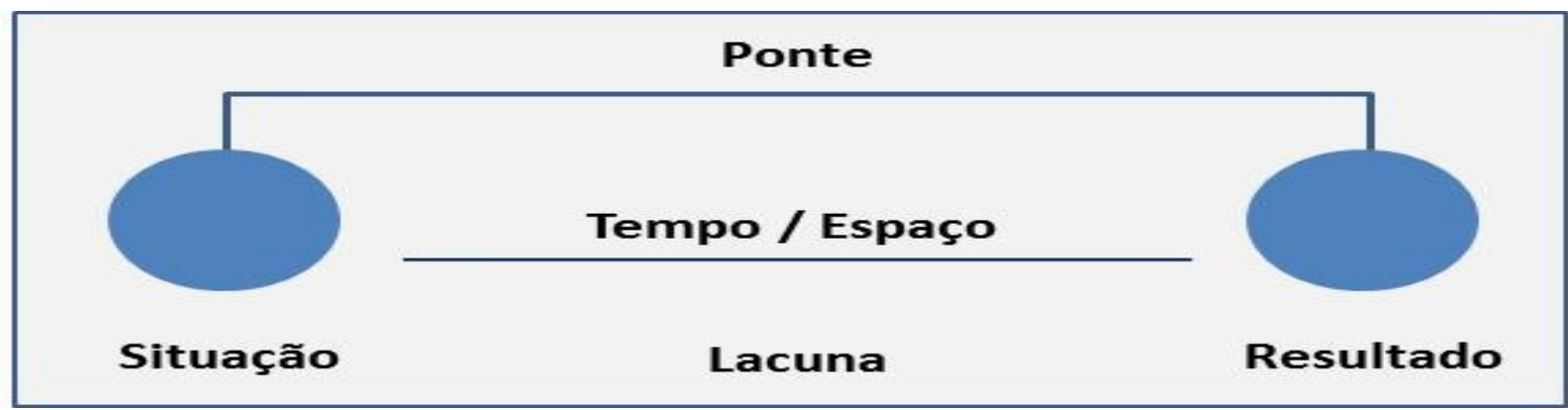

Fonte: Dervin (1986 apud GARCIA, 2007, p. 102) - Adaptação do Autor

Modelo Comportamental de Busca da Informação: modelo sem forma, não diagramático, voltado à abordagem de grupos de cientistas sociais dos departamentos da Universidade de Sheffield, com o objeto de propor um novo desenho de sistemas de recuperação da informação, gerando modelos a partir de padrões individuais de acordo com características definidas em iniciação (meios de busca), ligação (conexão referencial entre os materiais), navegação 
(procura casual), diferenciação (filtro da informação), monitoramento (seguimento de fontes), extração (seleção de documentos), verificação (checagem) e finalização (busca final). Existe uma inter-relação dessas características que depende das circunstâncias das atividades de busca do usuário e elas são mais bem definidas em seis etapas (Figura 5). (ELLIS, 1989 apud GARCIA, 2007):

- Iniciar: atividades que definem o começo da busca por informação e permitem uma visão geral do que será estudado, descobrindo informações que podem servir de base para uma ampliação posterior da busca - conversas, literatura de revisão, catálogos e índices -, situação relacionada à experiência e ao conhecimento prévio do assunto pelo pesquisador.

- Encadear: contato com citações que levam a outras fontes, criando conexões entre o que foi pesquisado e as novas informações.

- Navegar: busca semidirecionada a uma área de interesse geral

- Diferenciar: avaliação do material levantado por meio de comparação das fontes.

- Monitorar: verificação do desenvolvimento da pesquisa por meio do monitoramento das fontes de informação específicas.

- Extrair: trabalho sistemático em determinada fonte para extração de material de interesse.

Embora possam ser vistas como unificadas, as sequências podem variar. Uma hipótese de tal observação é a característica de um grupo maduro em pesquisa (cientistas), com comprometimento permanente com os estudos.

Figura 6 - Versão do processo de fases da estrutura comportamental de Ellis (1989).

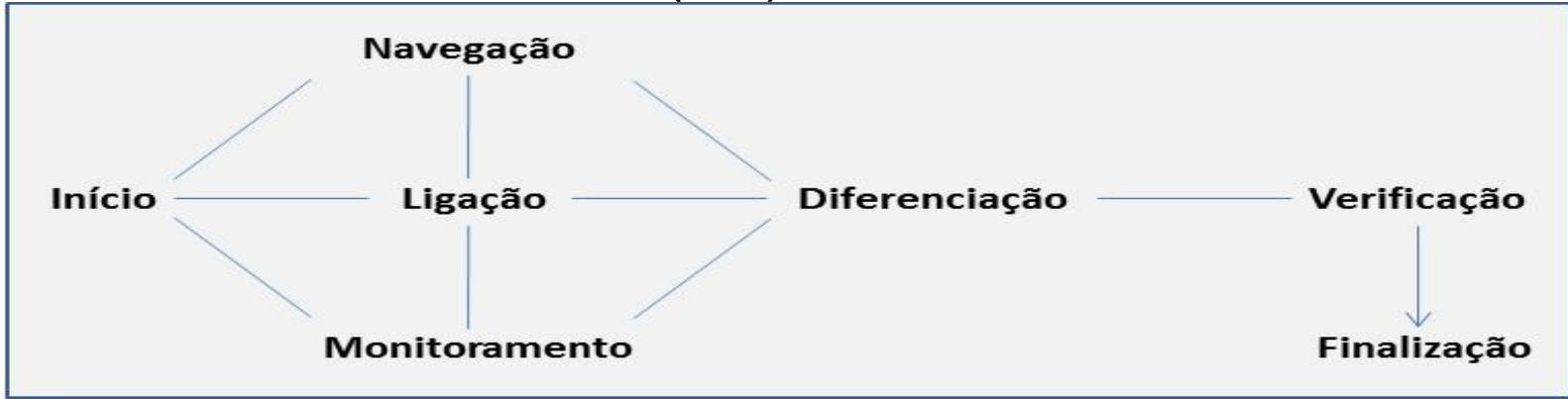

Fonte: Wilson (1999 apud GARCIA, 2007, p. 107) - Adaptação do Autor 


\section{Modelo Cognitivo do Processo de Recuperação da Informação:} modelo focado em identificar os processos de cognição nos elementos de processamento da informação. As funções de cada agente da informação usuário, autor do documento, intermediário, interface e sistema - são resultados dos modelos cognitivos do domínio de interesses particulares, que interagem e influenciam uns aos outros (Figura 6). (INGWERSEN, 2002 apud GARCIA 2007).

Figura 7 - Modelo cognitivo do processo de recuperação da informação (adaptado).

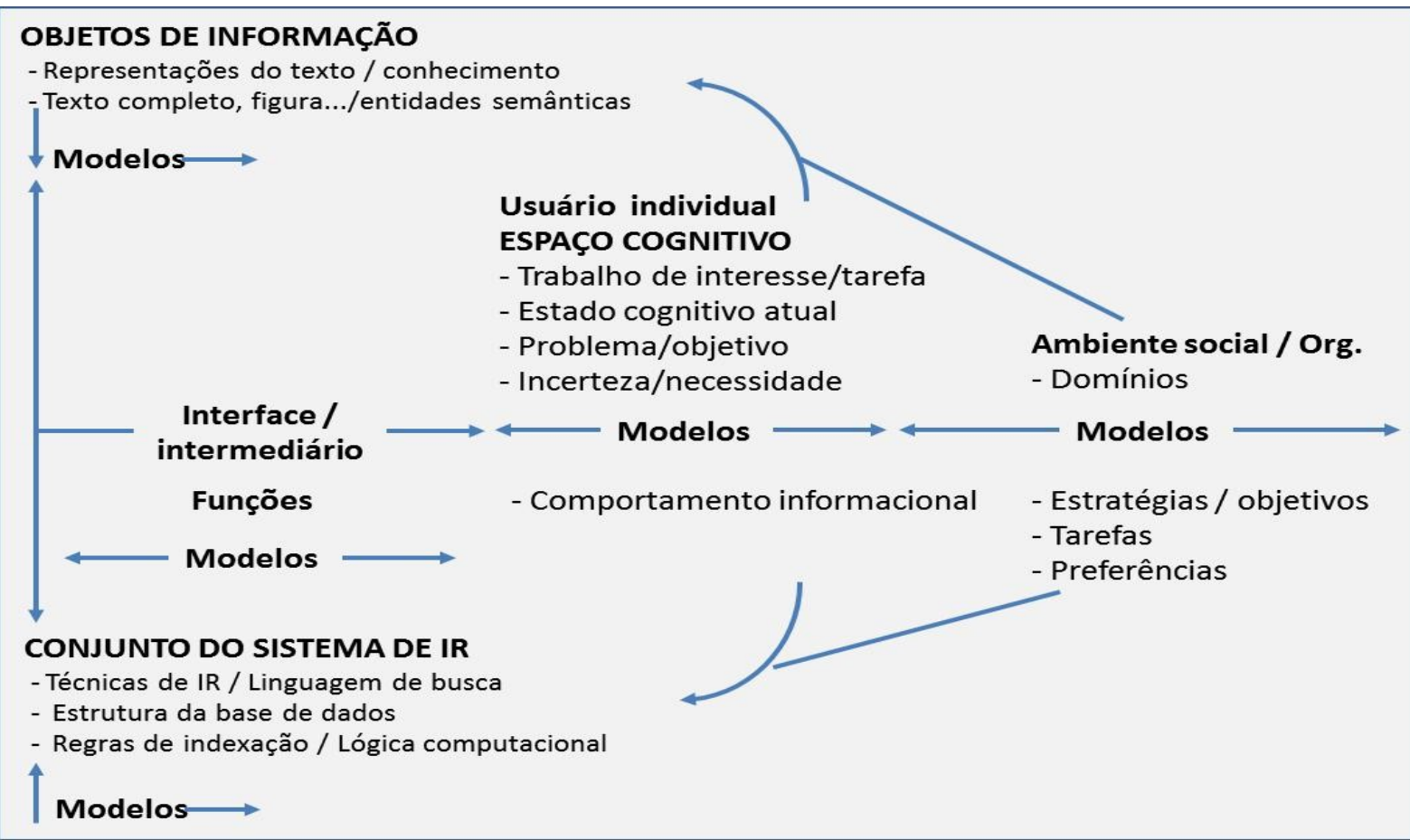

Fonte: Wilson (1999); Ingwersen (2002) (apud GARCIA, 2007, p. 109) - Adaptação do Autor

Como resultado deste estudo espera-se uma contribuição para o entendimento dos recursos da tecnologia colaborativa utilizados em ambientes informacionais digitais.

\section{CONSIDERAÇÕES FINAIS}

Com os modelos apresentados, concentrados no modo de busca e acesso à informação e desenvolvidos a partir da mesma abordagem - o usuário -, percebe-se que as representações a serem elaboradas pelos profissionais da informação necessitam considerar o contexto específico do usuário, fazendo-se 
valer de linguagens documentárias diversificadas e com maior qualidade, focando-se no conceito de organização e recuperação da informação, pois somente assim será possível mais precisão e competência nos resultados finais alcançados. Embora Kuhlthau e Ellis direcionem seus estudos no comportamento de busca e Wilson, Ingwersen e Dervin explorem mais o contexto, ambos os modelos são complementares, uma vez que a observação dos comportamentos e suas motivações tornam possível o desenvolvimento de sistemas de organização e representação da informação, que promovam abordagens que facilitem o comportamento humano de busca.

Os atuais SRI ou máquinas de busca possuem sofisticados processos de coleta, indexação, análise e interface de busca em que: linguagens e programas são utilizados para representar e descrever semanticamente a informação; ontologias para relações de domínio; bases de conhecimento (as chamadas bases secundárias com entidades descritas semanticamente) que fornecem dados estruturados para os agentes inteligentes; programas e tecnologias de visualização e apresentação dessa informação em contextos (Knowledge Graph ou mapa do conhecimento) nas interfaces de busca. Dessa maneira, um motor de busca faz parte de um sistema maior, que utiliza aplicativos (crawler, spider ou robô) para capturar palavras-chave e frases que identifiquem o conteúdo de uma página Web para indexá-la e armazená-la em sua base de dados (MONTEIRO et al, 2017)

Torna-se evidente, na Sociedade da Informação, a crescente relevância do investimento em pesquisas e abordagens que considerem o contexto contemporâneo, pois é este que define as necessidades, as competências a serem aprimoradas e as lacunas e falhas a serem modificadas. Nesse sentido, a questão é colocada em outro patamar, uma vez que interfere e influencia social e economicamente um país. A partir do momento em que a informação passa a adquirir valor econômico, saber utilizá-la e transformá-la em conhecimento é sinônimo de poder, pois somente o conhecimento aplicado pode desenvolver novos recursos e alavancar a economia.

As mudanças ocasionadas pela tecnologia usada para gerar, distribuir, acessar e usar a informação demanda por habilidades e competências 
relacionadas ao acesso, uso e disseminação da informação. É neste ponto que surge um novo usuário da informação com novas demandas por recursos computacionais e novas capacidades em produzir novos conhecimentos. Resulta desse procedimento que atualmente se conhece muita coisa sobre planejamento, aquisição, organização, controle e desenvolvimento de coleções, mas muito pouco sobre como as pessoas fazem uso dos sistemas ou para que fins, e como a informação, que é a matéria-prima do sistema, está sendo utilizada. Torna-se evidente a necessidade de aprofundar os estudos e pesquisas que permitam entender os modelos de busca e apropriação da informação em um cenário dependente de recursos computacionais na Web inteligente.

\section{REFERÊNCIAS}

BELLING, A.; RHODES, A.; SMITH, J.; THOMSON, S.; THORN, B. Exploring library 3.0 and beyond. 2011. Disponível em:

http://www.libraries.vic.gov.au/downloads/20102011_Shared_Leadership_Progr am_Presentation_Day_/exploring_library_3.pdf. Acesso em: 23 maio $201 \overline{8}$.

BEPPLER, F. D. Um modelo para recuperação e busca de informação baseado em ontologia e no círculo hermenêutico. 2008. Tese (Doutorado em Engenharia e Gestão do Conhecimento). Universidade Federal de Santa Catarina, Florianópolis, 2008.

CAREGNATO, S. E.; CRESPO, I. M. Comportamento de busca de informação: uma comparação de dois modelos. Em Questão. Porto Alegre, v. 9, n. 2, p. 271-281, jul./dez., 2003.

CANCLINI, N. G. Diferentes, desiguais e desconectados: mapas da interculturalidade. Rio de Janeiro: Editora UFRJ, 2009.

CAMPELLO, B. O movimento da competência informacional: uma perspectiva para o letramento informacional. Ciência da Informação, Brasília, v. 32, n. 3, p. 28-37, 2003.

CGI.BR/NIC.BR. Dimensões e características da WEB brasileira: um estudo do ".gov.br", 2011. Disponível em: http://www.cgi.br/publicacao/dimensoes-ecaracteristicas-da-web-brasileira/. Acesso em: 12 maio 2018.

DUDZIAK, E. A. Information literacy: princípios, filosofia e prática. Ciência da Informação, Brasília, v. 32, n. 1, p. 23-35, 2003 
FERREIRA, S. M. S. P. Novos paradigmas e novos usuários da informação. Ciência da Informação, Brasília, v. 25, n. 2, p. 217-223. 1995.

GARCIA, R. M. Modelos de comportamento de busca de informação: contribuições para a Organização da Informação. 2007. Dissertação (Mestrado em Ciência da Informação) - Faculdade de Filosofia e Ciências da Universidade Estadual Paulista, São Paulo, 2007.

GIL, A. C. Como elaborar projetos de pesquisa. São Paulo: Atlas, 1991.

LAKATOS, E. M.; MARCONI, M.A. Metodologia do trabalho científico. 2 ed. São Paulo: Atlas, 1991.

LOPES, I. L. Estratégia de busca na recuperação da informação: revisão da literatura. Ciências da Informação. Brasília, v. 31, n. 2, p. 60-71, maio/ago., 2002.

MELO, A. V. C.; ARAUJO, E. A. Competência Informacional e Gestão do Conhecimento: uma relação necessária no contexto da sociedade da informação. Perspectivas em Ciência da Informação, Belo Horizonte, v. 12, n. 2, p.185-201, maio/ago., 2007. Disponível em: http://www.scielo.br/pdf/pci/v12n2/v12n2a12.pdf. Acesso em: 16 jun. 2018.

MONTEIRO, S. D.; FERNANDES, R. P. M.; DECARLI, G. C.; TREVISAN, G. L. Sistemas de recuperação da informação e o conceito de relevância nos mecanismos de busca: semântica e significação. Encontros Bibli: Revista eletrônica de Biblioteconomia e Ciência da Informação, Florianópolis, v. 22, n. 50, p. 161-175, set. 2017. Disponível em: https://periodicos.ufsc.br/index.php/eb/article/view/1518-2924.2017v22n50p161. Acesso em: 31 mar. 2019.

PALETTA, F. C.; PELISSARO, B. Estudo de usuários e modelos de busca da informação. RDBCI: Revista Digital de Biblioteconomia e Ciência da Informação, Campinas, SP, v. 13, n. 1, p. 120-137, jan. 2015. Disponível em: https://periodicos.sbu.unicamp.br/ojs/index.php/rdbci/article/view/1584. Acesso em: 23 jul. 2018.

SQUIRRA, S. Sociedade do conhecimento. In: MARQUES DE MELO, J. M.; SATHLER, L. Direitos à Comunicação na Sociedade da Informação. São Bernardo do Campo, SP: UMESP, 2005.

TAKAHASHI, T. Sociedade da Informação no Brasil: livro verde. Brasília: Ministério da Ciência e Tecnologia, p.1-14. 2000.

W3C Brasil. Missão do W3C. Disponível em: http://www.w3c.br/Sobre/MissaoW3C. Acesso em: 12 maio 2011. 


\title{
MODELS OF INFORMATION SEARCH, ACCESS, RETRIEVAL, AND APPROPRIATION ON THE WEB OF DATA
}

\begin{abstract}
Introduction: The digital age demands new technical approaches to the use of Information Technology in the retrieval and appropriation of information in the context of the Web of Data. The development of this area will permit an increased understanding of the collaborative technology resources used in digital informational environments in information and knowledge organization. The insertion of these technologies consists in innovations that must be linked to the tradition and the mission of libraries and digital repositories. Objectives: This work aims to discuss the partial results of the research project carried out in the Information and Culture Department of the School of Communications and Arts of the University of São Paulo. This project is structured in three phases: (i) Models of information search, access, and retrieval; (ii) Technological infrastructure in digital libraries; and (iii) Tools for information search and retrieval on the Web of Data. Methodology: The research focused on the identification and discussion of the trends in information search models, especially those that influence the context of information organization and retrieval, so that the use of technology can promote the creation and aggregation of value to the models for the search, access, retrieval, and appropriation of information on the Web of Data. Conclusions: We currently know a lot about collection planning, acquisition, organization, control, and development, but very little about how the user interacts with the systems, to what ends, and how information, which is the raw material of the system, is being used. It becomes evident that there is a need to develop studies that allow us to further understand the models of information search and appropriation in a scenario of computational resources on the intelligent Web.
\end{abstract}

Descriptors: Information Search Models. Information Retrieval. Organization of Information. Information User. Information Technology. Web of Data.

\section{MODELOS DE BÚSQUEDA, ACCESSO, RECUPERACÍON Y APROPRIACÍON DE LA INFORMACÍON EN LA WEB DE DATOS}

\begin{abstract}
RESUMEN
Introducción: La era digital requiere de nuevas propuestas y enfoques técnicos asociados al empleo de las TIC (Tecnologías de la Información y la Comunicación) a la hora de recuperar y aprovechar la información en el contexto de la Web de Datos. Los avances en este ámbito proporcionarán una perspectiva más completa de los recursos tecnológicos utilizados en ambientes informáticos digitales para organizar la información y el conocimiento. La implantación de esas tecnologías aporta innovaciones que deben de estar vinculadas con la tradición y la misión de las bibliotecas y de los repositorios digitales. Objetivos: La finalidad de este trabajo consiste en difundir y discutir los resultados parciales de un proyecto de investigación realizado en el Departamento de Información y Cultura de la Escuela de Comunicaciones y Artes de la Universidad de São Paulo que se estructuró en tres fases: (i) Modelos de búsqueda, acceso y recuperación de la información; (ii) Infraestructuras tecnológicas para bibliotecas
\end{abstract}


digitales y (iii) Herramientas de búsqueda y recuperación de la información en la Web de Datos. Metodología: Primero, se identificaron los modelos de búsqueda de la información, en especial aquellos que influyen en la organización y recuperación de la información. Luego se fijaron y discutieron las tendencias observadas siempre desde la perspectiva del uso de la tecnología a la hora de contribuir a la creación y agregación de valor a los modelos de búsqueda, acceso, recuperación y aprovechamiento de la información en la Web de Datos. Conclusiones: En la actualidad se sabe bastante respecto a la planificación, adquisición, organización, control y desarrollo de colecciones, pero muy poco sobre cómo interactúa el usuario con los sistemas o qué fines pretende, ni sobre cómo se emplea después la información que es la materia prima del sistema. Es evidente la necesidad de profundizar en estudios e investigaciones que permitan entender los modelos de búsqueda y aprovechamiento de la información en un escenario dependiente de recursos informáticos en la Web inteligente.

Descriptores: Modelos de Búsqueda de Información. Recuperación de la Información. Organización de la Información. Usuarios de Información. Tecnologías de la Información. Web de Datos. 